\title{
The Deficiency and Remedy of Language Course Features in Higher Vocational Colleges

\author{
Xiaomei Li
}

Jingchu University of Technology, Jingmen 448000, Hubei, China

E-mail: 50833870@qq.com

Key words: Higher Vocational Colleges; Language Course Features; Deficiencies and Remedies

\begin{abstract}
Curriculum design is the core content of teaching planning. However, higher vocational colleges lack their own characteristics in language courses. The author thinks that integrating language and teaching contents; giving attention to the depth and breadth of students' language knowledge; combining majors with minor subjects are effective ways to make up for the deficiency of language courses in higher vocational colleges.
\end{abstract}

\section{高职院校语言类课程特色的缺失与弥补}

\author{
李晓梅 \\ 荆楚理工学院外国语学院, 荆门, 448000, 湖北, 中国 \\ E-mail:50833870@qq.com
}

关键词: 高职院校; 语言类课程特色; 缺失与弥补

摘要：课程设置是教学规划的核心内容, 语言类课程在高职院校中占有相当大的比重。高职 院校具有其独特的优势, 但在语言类课程中却缺乏自身特色。笔者认为, 高职院校可在职业 技能引导下, 融合语言与内容, 打造语言类通识课程; 推出语言类精品特色课程; 将主修与 辅修相结合, 在实践中内化语言类通识课程; 鼓励教师开设前沿课程等方式来弥补高职院校 语言类课程特色的缺失, 优化语言类课程教学效果。

\section{1. 引言}

在高职院校课程中，语言类课程占有相当大的比重。课程设置作为教学规划的核心内容, 是完成教学目标，执行教学内容的主要途径。高职院校同时兼具 “高等性” 和 “职业性” 的 特点, 肩负着培养国家高级型职业人才的重任。因此, 高职院校学生语言类课程设置需要特 色化。高职院校具有其独特的优势, 但在其语言类课程中却缺乏其自身特色。针对以上问题, 对语言类特色课程的增加及弥补势在必行。完善语言类的特色课程对于优化课程结构, 培养 多元化人才, 适应社会发展需求具有积极的推动作用。

\section{2. 课程设置与人才培养之间的关系}

高职院校的教育目标是 “培养适应社会需要的复合型人才”，合理的课程设置是学校人 才培养的核心。因此, 拥有与时俱进的课程发展理念和不断更新的课程内容设置是高校发展 和改革的关键。高职院校主要的培养目标是高素质技能、应用型人才。因此, 以能力培养为 本位, 以职业技能为导向的课程设置应该成为各学院课程发展的特色, 成为高职院校职业教 育稳定发展的有力保障。 


\section{3. 高职院校语言类课程设置现状}

近年来, 在国家相关政策指引下, 语言类课程研究学者们在课程设置、教学方法及教学 内容上做出了许多研究和探索, 取得了不少成就, 但也存在不足之处, 主要梳理为以下几个 方面:

\section{1 理论陈旧, 实践问题多}

语言类课程作为培养学生语言运用及交际能力的一门课程, 其教学目标为 “系统掌握语 言知识, 提高语言修养, 最终形成较好的口头及书面表达能力。”随着对语言类课程的专业 性质、课程特点及专业人才目标认识的不断深入, 我们的课程设置有了许多新的进步。但在 总体上说来, 语言类课程仍旧 “重理论, 轻实践”。目前现行模式仍然反应的还是六十至七 十年代国际语言教学的理论认知水平。随着研究的不断深入, 其实践并未与理论相结合, 也 并没有跟上时代的步伐, 与时俱进。近三十年来, 国内外在语言学、二语习得等与语言教学 相关的领域研究中取得了丰硕的成果, 研究成果及实验结论数不胜数。但是这些研究成果在 实际教学中, 并没有被推广和普及, 有些教学模式还仍停留在理论探索阶段, 并没有在实际 教学中进行实践检验和论证。

\section{2 语言类通识课程中显性课程与隐形课程比例失衡}

美国学者帕卡德（A.S.Packard）曾指出, “所谓通识教育，是指涵盖古典学、文学和科 学方面的相关课程内容。通识课程为学生提供所有知识分支的教学, 旨在使学生学习一种专 业的、特殊的知识之前对知识的总体状况有一个综合、全面的了解。” 因此, 就内容而言, 通识教育是一种涉及范围广、覆盖面宽、非专业、非功利性的基础技能教育。从某种意义上 来说, 高校的通识课程分为两类: 即显性课程和隐性课程。显性课程指的是根据学校人才培 养计划及教学大纲展开的有计划、有组织的 “课堂内课程” ; 而隐性课程则是指具有潜在性 和隐藏性的非正式和非计划性的 “课堂外课程”。然而, 很多高职院校却只注重理论知识的 灌输, 却忽略了人格的教化和文化的传承, 使得语言类课程具有功利性色彩, 也削弱了隐性 课程的地位, 使得显性课程与隐性课程比例失衡。

\section{3 核心结构课程缺少应有特色, 忽视教法}

国家教育部门高度关注高职院校的课程设置改革问题，提出了“开放、实践、职业”的 指导原则。然而目前高职院校学生实践经验缺乏, 应用能力不能满足社会发展需求, 成为目 前高职院校学生就业体系中的主要矛盾之一。追根溯源仍然是高职院校的核心结构课程缺少 应有的特色。目前, 高职院校的语言类课程及专业建设仍然是对普通高校的简单复制和模拟 借用，没有真正体现出高职教育应有的特色。

\section{4. 高职院校语言类课程的特点及其功能}

学习语言类课程的目的是为了传承文化。《周易》中有记载: “刚柔交错, 天文也; 文 明以止, 人文也。”任何通识类课程中都涵盖人文价值的维度, 习近平同志在十九大会议中 指出, “优秀文化凝聚着民族精神和文化财富, 是社会发展的深厚基础, 也是国家建设的重 要支撑。”语言类课程作为高职教育中的通识类基础课程, 肩负着 “全面提高学生的文字、 文学和文化修养” 和 “正确把握语言课程中丰富的人文内涵及外延” 等目标。因此, 任何学 科的学习首先是为了传承优秀文化, 语言作为思想表达的载体, 更是如此。

其次，语言类课程的学习还为了培养治学治事的应有能力。所谓治事，并非某项具体技 能, 而是指全面适应的工作能力。其内涵及外延包括中英文双语交流和书面表达能力和对社 会发展的认知能力等。而治学能力则是指学生获取知识及认知事物本质的方法, 是独立寻求 
知识、解决问题的意愿及能力。治事及治学也是高职学生终身学习的重要理念之一, 这个过 程也是由浅及深, 由宽广到专业, 由认知到应用的过程。

\section{5. 高职类院校语言类课程特色的弥补规则}

\section{1 语言与内容相融合的思路, 打造语言类通识课程}

学科课程在学校教育课程中占有最大的比例, 此乃学生职业诉求的具体体现。因此, 高 职院校和学生均对这一部分给予了很多关注。在语言类课程改革的实践中, 首先应当结合高 职院校的培养目标和学生未来的职业就业定位来开发及改进本校课程, 引进新的学科前沿知 识和理念。具体来讲, 应当将语言学习与学科内容相融合, 全面打通文、理、社科类课程门 类，并将通识教育贯穿于整个高职学习周期中。具体说来，高职语言类课程中可以将文学、 文化、多语种语言相结合, 以母语及多门外语为媒介, 挑选不同文化中的现象或文学作品中 的案例, 以讲座或研讨会形式展开。这样的语言类课堂内容不仅培育学生运用语言进行思维 的能力, 也可以培养学生的美学情怀和综合人文素养。教师可以将这门课程打造成充满浓郁 的人文思想色彩、引领学生独立思考的专业语言类特色课程, 进而也可以为全校学生提供选 修的成长及鉴赏机会。

\section{2 厚基础, 传承文化, 兼顾深度与广度, 推出语言类精品特色课程}

课程中理念是精髓。没有正确清晰的课程理念, 课程的设置和实施都无法落实。随着我 国高等教育的专业设置不断细化, 高职教育首先应树立厚基础、重应用、多元为本、顺应社 会需求的核心理念。在语言教学中，“语言”二字涵盖多重意义，除了听、说、读、写等基 本技能外, 还涵盖语言艺术、经典欣赏、文学创作、语境及话语意识和语言文学学习等内容。 1994年美国学者Picker提出, “语言类学习同其他学科不同, 语言是人脑中一项复杂而独特的 生物装置，思维的输入与产出不同于任何情况下信息处理的能力或认知行为。”因此，高职 院校中语言类课程的改革思维应该定位在以未来职业需求为导向, 培养具有扎实的语言能力 和广泛的文化文学知识的应用型人才为目标。在这个大的思路框架之下, 在课程体系中, 推 出语言类精品特色课程, 同时使得通识课程得以兼顾深度与广度, 来有效弥补语言类课程特 色中的不足，保障高职类院校人才培养目标的完成。

\section{3 以职业技能为导向，将主修与辅修相结合，力求在实践中内化语言类通识课程}

职业技能，指的是在职业活动中为了能够顺利执行而必备的相关知识、技能、情感认知 和个性心理特征的综合。就语言类课程的职业技能而言, 就是使学生所学到的语言知识转化 为未来职业生涯中的语言交际能力和写作技能, 并受熏陶塑造, 最终达到情感塑造的技能。 语言类课程不仅理论性强，实践性也很强。例如：新闻类专业毕业生不仅要了解汉字的规范 使用规则, 随着互联网的日趋蓬勃发展, 还应具备网络用字、异形字、术语、方言词语等用 法; 再比如, 英语专业的学生, 不仅要熟练使用英语, 还应根据未来职业走向, 了解与职业 相关通用英语及行业英语等。因此，高职院校的语言类特色课程的弥补规则不仅要深化 “主 修” 类课程, 关键还在于将跨学科的辅修类课程与之相结合, 且语言类的辅修课程应关注社 会现实与社会需求, 以服务社会、强调应用、注重实践为导向, 将静态的理论知识与动态的 实践技能合二为一, 向内提升学生知识能力, 向外拓展学生实践技能, 实现以职业技能为导 向的 “语言表达能力” 的目标。

\section{4 鼓励教师开设前沿课程, 并彰显自身特色}

近年来, 国内语言学学者在不断探索, 在语言学领域不断创下新的研究成果。语言类课 程特色的弥补还应在于大力鼓励教师融合中国传统语言学与西方理论, 拓展师生的国际化视 野, 开设前沿课程。孔子有言, “教学相长”。前沿知识和科研成果能够使学生较全面地接 
触到涉及该课程的最新研究成果。除此之外, 高职院校建设具有高职特色的语言课程, 还应 该在民族多元化和国际交流日益频繁的背景下, 预见未来行业对高职人才的语言类课程要求, 依照各自的地域特色有效利用各自的课程、教学、师资资源和学校的不同专业特色开发出多 层次的课程体系, 打造出各自特色的高职类语言课程。特色课程的开发和设置, 不仅是各高 职院校个性和特点的体现, 同时也是对自身各项教学资源的整合。我国地大物博, 疆土辽阔, 历史绵长, 人文荟萃, 因此不同的地域也存在着较大的地域文化, 而这些地域文化差异资源 正好可以为教育教学所妥善利用。特色和前沿的语言类课程, 不仅可以提高学生的竞争力, 也可以关照学生发展的多元化需求, 实现人尽其才的发展初衷。

\section{6. 结束语}

课程设置是教学计划的核心内容, 也是实现教学目的、落实分解教学内容的具体路径。 高职院校中语言类课程特色的弥补规则, 还应以整个学校的人才培养方案为主体依据, 以这 个时代整个高校发展为主要参考。语言类专业课程的合理设置, 也在很大程度上决定了学生 的知识体系和知识结构, 决定着学生的语言能力和综合素养。因此, 高职类院校的语言类课 程, 应当不断探索和改进, 运用最新的语言学等理论, 不断探索课程结构, 优化课程内容, 突出高职院校的语言类课程特色，以适应新时期语言和文化发展的需求。

\section{致谢}

本文为2017年荆楚理工学院教研项目 (JX-201729)；2017年湖北省教育科学规划项目 （2017GB080）的阶段性成果之一。

\section{References}

[1] Honghua Deng \& Teng Li, On the Reform of the Chinese-Related Course Teaching in Modern Times, Education and Teaching Research, vol. 4, pp.72-75,2015.

[2] Jigang Cai, Brand New Teaching Philosophy and Methodology: A Study of English for Academic Purposes and College English, Int.J. Foreign Language Teaching Theory and Practice, vol.2, pp. 1-7, 2014.

[3] Yuming Li, Some Thoughts on Foreign Language Planning in China, Journal of Foreign Languages, vol. 33, pp.2-8, 2010.

[4] Yingjian Guo, English and American Literature Teaching in the Context of Globolization, Beijing:Central University for Nationalities Press, pp. 236-241, 2014.

[5] Luting Ma, Reflections on the Construction of Applied Technology Universities, China Higher Education, vol.10, pp.10-14, 2014. 